\title{
Information needs of early-stage prostate cancer patients: within- and between-group agreement of patients and health professionals
}

\author{
Peter Rüesch • René Schaffert • Susanne Fischer • \\ Deb Feldman-Stewart • Robin Ruszat • Peter Spörri • \\ Markus Zurkirchen • Hans-Peter Schmid
}

Received: 24 June 2013 / Accepted: 12 November 2013 / Published online: 28 November 2013

(C) The Author(s) 2013. This article is published with open access at Springerlink.com

\begin{abstract}
Purpose The aims of this study were to analyze agreement on information needs within a group of early-state prostate cancer patients and to compare information preferences of patients with the view of health-care professionals about patients' needs.

Methods Sample consists of patients $(n=128)$ and six subgroups of health-care professionals (urologists, $n=32$; nurses, $n=95$; radiotherapy technologists (RTTs), $n=36$; medical oncologists, $n=19$; radiation oncologists, $n=12$; general practitioners (GPs), $n=10)$. Information needs have been assessed with 92 questions concerning prostate cancer and its treatment. Respondents judged the importance of addressing each question. Within- and between-group agreements of patients and health-care professional groups were estimated with raw agreement indices as well as chance-corrected Kappa and Gwet's $\mathrm{AC} 1$ measures. Finally, group-specific core items rated with high importance as well as high agreement were defined.
\end{abstract}

P. Rüesch $(\bowtie) \cdot$ R. Schaffert

Research Unit for Health Services Research, School of Health

Professions, Zurich University of Applied Sciences,

CH-8401 Winterthur, Switzerland

e-mail: rech@zhaw.ch

R. Schaffert

e-mail: shar@zhaw.ch

\section{S. Fischer}

Evaluation Office, University of Zurich,

CH-8001 Zurich, Switzerland

e-mail: fischer@evaluation.uzh.ch

D. Feldman-Stewart

Division of Cancer Care and Epidemiology, Cancer Research Institute, Queen's University, Kingston, ON K7L 3 N6, Canada e-mail: Deb.Feldman-Stewart@krcc.on.ca

\section{R. Ruszat}

Department of Urology, Clara Hospital, CH-4058 Basel, Switzerland

e-mail: robin.ruszat@claraspital.ch
Results Patients rated on average (median) half, i.e., 51 out 92 items as essential (interquartile range $(\mathrm{IQR})=36-66), 26$ items as desired ( $\mathrm{IQR}=14-38$ ), and 10 items as avoidable ( $\mathrm{IQR}=2$ 22). Within-group agreement on the presented information topics is modest for any participating group $\left(\mathrm{AC}_{\text {patients }}=\right.$ 0.319; $\left.\mathrm{AC} 1_{\text {professionals }}=0.295-0.398\right)$. Agreement between patients and professionals is low too $(\mathrm{AC} 1=0.282$ 0.329). Defining group-specific core sets of information topics results in 51 items being part of at least one core set. Concordance of the item core sets of patients and professionals is moderate with $\kappa=0.38-0.66$, sensitivity of professionals' core sets for patients' preferences varies between 56 and $74 \%$.

Conclusions Results emphasize the need for dialogue between doctor/professional and patient in identifying the information needed by individual patients and support the importance of shared decision making.

P. Spörri

Department of Urology, Hospital of the Canton of Solothurn,

CH-4600 Olten, Switzerland

e-mail: peter.spoerri@spital.so.ch

\author{
M. Zurkirchen \\ Department of Urology, Hospital of the Canton of Zug, \\ CH-6340 Baar, Switzerland \\ e-mail: markus.zurkirchen@zgks.ch
}

H.-P. Schmid

Clinic of Urology, Hospital of the Canton of St. Gallen,

CH-9007 St. Gallen, Switzerland

e-mail: hans-peter.schmid@kssg.ch 
Keywords Prostate cancer · Patient information needs . Shared decision making $\cdot$ Patient-physician communication . Health professionals' opinions

\section{Introduction}

Patients newly diagnosed with localized prostate cancer are faced with several treatment options such as watchful waiting or active surveillance, radical prostatectomy, radiation therapy, as well as others. Each treatment has its benefits as well as its risks and harms. However, scientific evidence on the efficacy of these treatments is still limited, in particular, long-term randomized clinical trial data are lacking $[1,2]$. Thus, to decide on a specific therapy is a complex undertaking for patients by having to consider a variety of often sophisticated data.

Some prostate cancer patients want to know as much as possible about their disease and its treatment [3-5] but are overwhelmed by the complexity of information presented at the same time [6-8]. Therefore, patients are strongly in need of advice by the physician, and most patients wish to be involved actively in the treatment decision process. It is therefore not surprising that satisfaction with information received on illness and therapy is positively correlated with quality of life of prostate cancer patients after treatment $[3,9]$.

However, patients often report that their information needs were not satisfactorily met [10-12]. There seems to be also much heterogeneity with regard to amount and quality of information delivered by professionals $[6,11]$. A majority of studies are limited to the counseling of patients by urologists, whereas the specific role of other health professionals is neglected. However, the literature on multidisciplinary cancer care underlines the benefit for patients cared of by a multidisciplinary team of specialists [13-15]. In particular, some research proves that the use of specialist nurses in prostate cancer care results in better covering of patients' information needs [16]. Besides, research suggests that the patients' decision making on a specific therapy option is highly dependent on the professional background of the consulting health specialist [17-19]. To summarize, information needs of prostate cancer patients are broad and manifold, and health professionals counsel patients quite inconsistently as well. Therefore, the present study addresses two main complexes of questions:

1. Agreement within and between groups of patients and health professionals, i.e.: To what extent do patients agree among themselves on specific information topics they want to be addressed in relation to prostate cancer and its treatment? And to what extent do health professionals, being involved in the treatment and care of prostate cancer patients, agree on information to be delivered to patients?
Finally, do professionals' ratings of information topics correspond to patients' needs?

2. Patients' and professionals' core sets of vital information topics: Is it possible to derive core sets of information topics on prostate cancer being essential from the view of patients as well as professionals? To what degree do patients' and professionals' core sets overlap?

\section{Methods}

Design

The present study comprises two groups of participants, patients with established diagnosis of localized prostate cancer and health professionals engaged in the treatment of these patients. Both groups were provided with the same questionnaire developed by a Canadian research group led by Feldman-Stewart [5] and found to be appropriate for prostate cancer patients in eight other countries [20]. It consisted of 92 information topics about prostate cancer and its treatment. Patients had to rate the importance of each item retrospectively with regard to their decision making on choosing a specific treatment option. Professionals had to rate the information topics the same way, however, by trying to adopt the patient view.

\section{Samples}

Patient sample The study population encompasses patients with established diagnosis of prostate cancer fulfilling the following additional selection criteria:

- Localized tumor stage (T1 or T2, PSA $<20 \mathrm{ng} / \mathrm{mL}$, Gleason score $<8$ ),

- Having obtained diagnosis 3 to 24 months before date of study,

- Being treated in one of four urology departments of clinics in the German-speaking part of Switzerland.

Of the 330 patients fulfilling the abovementioned criteria for inclusion, 179 (54\%) answered the questionnaires. Finally, 51 patients had to be excluded from the study sample because of invalid questionnaires or time of diagnosis dating back more than 24 months. The final study sample consists of $n=128$ patients (mean age $=66$ years). An analysis of response rates by age and type of treatment indicates no age-related differences. However, the response differed by type of treatment with a low rate $(36 \%)$ for patients who had received radiotherapy.

Health professionals sample In order to achieve comparability with the study by Capirci et al. [21], the same health-care 
professionals were to be included. Therefore, the study population encompasses health professionals involved in treating prostate cancer patients in the 12 months prior to study date. Samples of physicians were drawn from the registry of the Swiss Medical Association (FMH) with sample sizes of $n=$ 100 per group (exception: radiation oncologists, $n=47$ ). Nurses and radiotherapy technologists (RTTs) were recruited from the participating centers with $n=197$ nurses and $n=45$ RTTs contacted. The final professional sample that could be used for analysis consisted of the following: 32 urologists (response rate $=32 \%$; mean age $=47$ years; proportion men $=$ $100 \%), 19$ medical oncologists $(19 \% ; 47 ; 68 \%), 11$ radiation oncologists (23\%; 47; $75 \%), 36$ RTTs (73\%; 35; $14 \%), 11$ general practitioners (GPs) (11\%; 54; $60 \%)$, and 99 nurses $(50 \%, 38 ; 16 \%)$. Total sample size was $n=208$ health professionals.

\section{Instrument}

The questionnaire used was developed by Feldman-Stewart et al. [5] based on interviews with prostate cancer patients, their family members, and medical experts. It was revised in further studies and then used internationally. The authors of the instrument paid attention to cover all possible aspects that may be relevant for those involved in the therapeutic decision making. This work resulted in a set of 92 questions referring to the epidemiology and natural history of prostate cancer, the effectiveness and side effects of treatments, and the experience of the professionals. Patients were asked to go back in their mind to the time of treatment decision and to indicate for each item and how important it was for their decision making. The importance of items had to be rated by using four possible categories: "no opinion," "avoid," "desired," or "essential." Health professionals had to judge the same 92 items in the same way, however, by taking the view of a hypothetical prostate cancer patient prior to the treatment decision. In order to ensure that each participant refers to the same situation, he/ her was provided with a vignette of a hypothetical prostate cancer patient. After judging the importance of addressing the various questions, the participants filled out a form providing further demographic and professional background information.

\section{Statistical analyses}

Two types of concordance were analyzed: (1) concordance of judgments within a specific group of participants (i.e., within patients, and within professionals) and (2) concordance of judgments between groups, e.g., patients and urologists. To express concordance, we use inter-rater agreement coefficients. The appropriate measure of inter-rater agreement for our data structure is Fleiss' Kappa $(\kappa)$ coefficient [22], an extension of the $\kappa$ measure of Cohen [23]. However, $\kappa$ statistics can be inadequately biased by the variation of the trait prevalence rate and by the magnitude of raters' classification probabilities [24]. Gwet [25] proposed an alternative agreement measure, the $\mathrm{AC} 1$ for categorical data. We will report both measures, the unweighted Fleiss' $-\kappa$ as well as the unweighted $\mathrm{AC} 1$ for multiple raters and multiple subjects.

Usually, agreement coefficients measure concordance of two or more raters' judgments on one or more subjects. However, we are also interested in measuring the agreement between groups of raters, in particular, agreement of patients and professionals. Technically speaking, we need to analyze the judgments on multiple subjects of all possible pairs of one rater group with another rater group. We derived the between-group agreement measure according to the following equation:

$C_{1 \times 2}=\frac{C_{1+2}-\left(\left(C_{1} * w_{1}\right)+\left(C_{2} * w_{2}\right)\right)}{w_{1 \times 2}}$

with:

- $C_{1 \times 2}=$ between-group agreement coefficient of group 1 ratings paired with group 2 ratings

- $C_{1+2}=$ total agreement coefficient of pooled group 1 and group2 ratings

- $C_{1}, C_{2}=$ within-group agreement coefficients of group 1 and group 2

- $w_{1}, w_{2}, \mathrm{w}_{1 \times 2}=$ weights for group 1 and 2 as well as for the combination of both groups.

The calculation of group weights is presented in the Appendix of this paper. Statistical analyses as well as the calculation of Fleiss' Kappa were done with STATA SE 11. AC1 coefficients were calculated by using AgreeStat, an EXCEL VBA program developed and distributed by Gwet. ${ }^{1}$

\section{Results}

Distribution of item ratings

Figure 1 illustrates that patients rated on average (median) around half, i.e., 51 out 92 items, as essential (interquartile range $(\mathrm{IQR})=36-66), 26$ items as desired $(\mathrm{IQR}=14-38)$, and 10 items as avoidable or not assessable ( $\mathrm{IQR}=2-22)$. The variation of patient responses is large. This pattern of large within-group variance holds mostly true for professionals too with the exception of urologists' ratings being somewhat more consistent compared to other groups.

In general, the variation of responses to each judgment category is much larger within groups than between groups of participants: one-way ANOVA of category-specific item responses by group of subjects provided small intraclass

\footnotetext{
${ }^{1} \mathrm{http}: / /$ agreestat.com/agreestat.html
} 


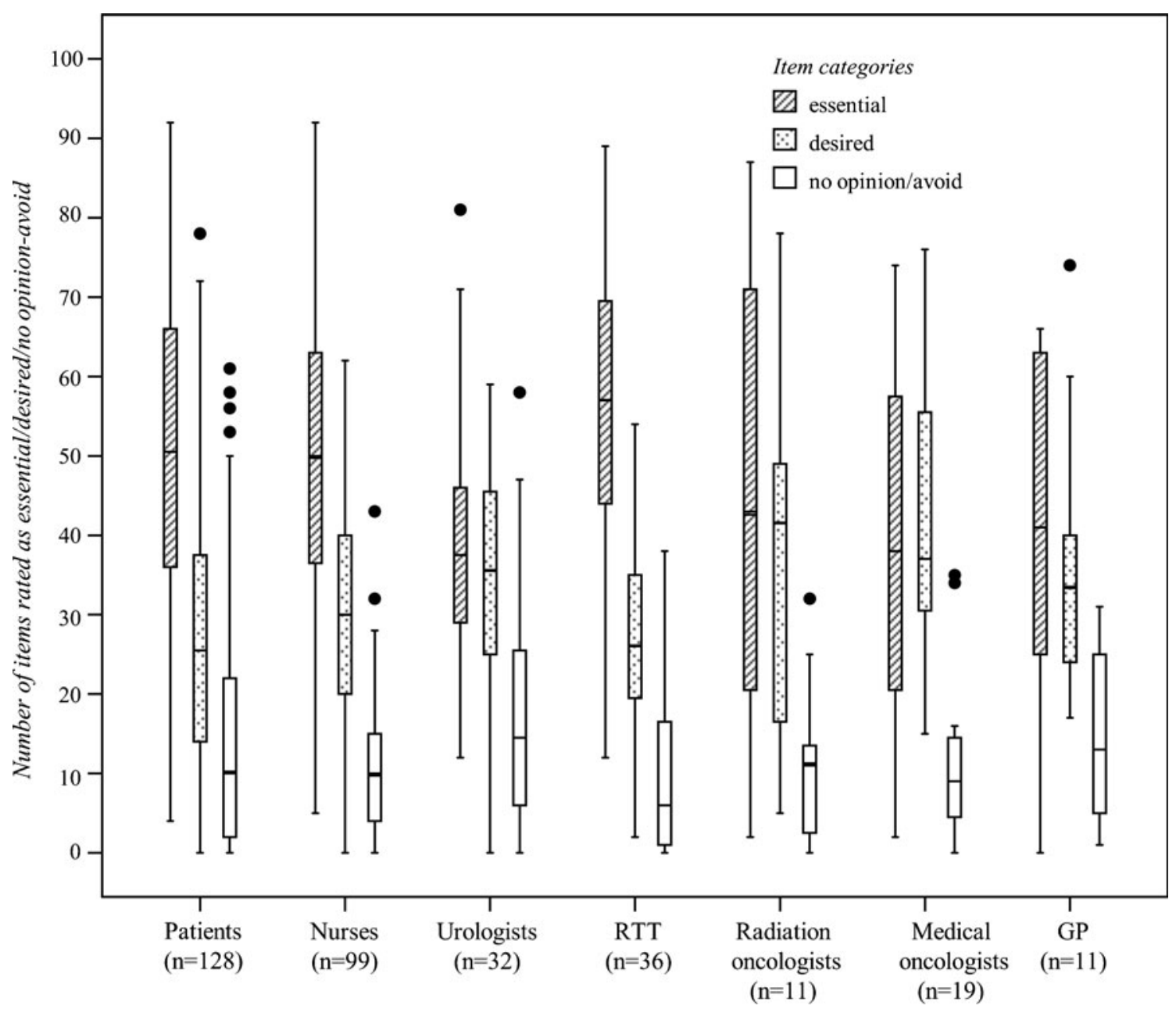

Fig. 1 Boxplots of number of items judged as "essential", "desired," or "avoid"/“no opinion" by patients and health professionals (maximum number of items $=92$ )

correlation such as $\rho=0.059$ (95\% confidence interval (CI) $=$ $0.000-0.161 ; F=3.57 ; p=0.002)$ for "essential." Quite similar results are provided for the remaining response categories such as "desired" with $\rho=0.070(0.000-0.187 ; 4.11 ; 0.001)$ and "avoid/no opinion" with $\rho=0.016(0.000-0.012 ; 1.68 ; 0.124)$.

Within- and between-group agreement on importance of judgments

Due to small sample size, we merged medical and radiation oncologists to one group and excluded GPs from the following analyses. First, we calculated for each group of participants, their raw agreement as well as chance-corrected agreement of ratings using Fleiss' Kappa $(\kappa)$ and Gwet's AC1. With regard to overall raw agreement, results (Table 1) indicate that participants within a specific group agree on their ratings by around half of the total item set. Inspecting category-specific ratings reveals substantial raw agreement on the item categories "essential" and "desired," whereas agreement on the categories "avoid" and "no opinion" is weak. However, by correcting for chance agreement, coefficients become small to moderate depending on type of measure. Finally, the $95 \%$ CIs indicate that groups do not differ significantly from each other with regard to the amount of within-group agreement.

Second, we calculated between-group agreement (cf. "Methods" and Appendix). Agreement between patients and professionals varies between $\kappa=0.067-0.096$ and $\mathrm{AC}_{1}=$ $0.282-0.329$ and is comparably small like within-group agreement. The same holds true for agreement between different professional groups varying from $\kappa=0.085-0.109$ and $\mathrm{AC}_{1}=$ $0.287-0.363$.

Agreement between patients' and health professionals' item core sets

We tried to build core sets of significant items for each study group (i.e., patients, health professionals). We defined "significant" as follows:

- an item is rated with high importance ( $\geq 67$ th percentile of the distribution of item means) and 
Table 1 Within- and between-groups agreement of patients and health professionals about information topics on prostate cancer and its treatment

\begin{tabular}{|c|c|c|c|c|c|c|c|}
\hline & \multicolumn{2}{|c|}{ Chance-corrected agreement } & \multicolumn{5}{|c|}{ Raw agreement } \\
\hline & Kappa (95% CI) & $\mathrm{AC} 1(95 \% \mathrm{CI})$ & Overall & -1 & 2 & 3 & -4 \\
\hline \multicolumn{8}{|l|}{ Within groups } \\
\hline Patients & $0.085(0.067-0.104)$ & $0.319(0.277-0.361)$ & 0.454 & 0.040 & 0.200 & 0.323 & 0.607 \\
\hline Nurses & $0.103(0.080-0.126)$ & $0.349(0.303-0.394)$ & 0.476 & 0.061 & 0.170 & 0.359 & 0.622 \\
\hline Urologists & $0.146(0.117-0.175)$ & $0.295(0.251-0.338)$ & 0.447 & 0.103 & 0.266 & 0.408 & 0.576 \\
\hline RTT & $0.090(0.067-0.112)$ & $0.398(0.349-0.447)$ & 0.507 & 0.071 & 0.105 & 0.320 & 0.666 \\
\hline Oncologists & $0.096(0.064-0.127)$ & $0.308(0.281-0.336)$ & 0.449 & 0.049 & 0.196 & 0.460 & 0.520 \\
\hline \multicolumn{8}{|l|}{ Between pairs of groups } \\
\hline Patient-Nurses & $0.077(0.057-0.096)$ & $0.285(0.242-0.328)$ & & & & & \\
\hline Patient-Urologists & $0.096(0.076-0.116)$ & $0.282(0.242-0.322)$ & & & & & \\
\hline Patient-RTT & $0.067(0.050-0.083)$ & $0.329(0.287-0.372)$ & & & & & \\
\hline Patient-Oncologists & $0.077(0.058-0.096)$ & $0.294(0.264-0.324)$ & & & & & \\
\hline Nurses-Urologists & $0.099(0.081-0.117)$ & $0.288(0.249-0.326)$ & & & & & \\
\hline Nurses-RTT & $0.087(0.069-0.105)$ & $0.363(0.321-0.404)$ & & & & & \\
\hline Nurses-Oncologists & $0.086(0.066-0.105)$ & $0.301(0.273-0.329)$ & & & & & \\
\hline Urologists-RTT & $0.091(0.075-0.108)$ & $0.292(0.248-0.336)$ & & & & & \\
\hline Urologists-Oncologists & $0.109(0.089-0.128)$ & $0.287(0.258-0.315)$ & & & & & \\
\hline RTT-Oncologists & $0.085(0.069-0.102)$ & $0.311(0.281-0.340)$ & & & & & \\
\hline
\end{tabular}

Answer categories:_1="avoid,"_2="no opinion,”_3="desired,”_4="essential”

Kappa unweighted Fleiss' Kappa, $A C 1$ unweighted Gwet's AC1 for multiple raters and multiple subjects

- high agreement $(\geq 67$ th percentile of the distribution of item specific raw agreement) within a sample.

These two rules produce group-specific core sets. The accordance between the patients' core set of important items and a professionals' core set can then be calculated. Furthermore, the sensitivity (as well as specificity) of professionals' core set with regard to patients' core set can be estimated. Sensitivity is interpreted as a measure of how well the judgments of a specific professional group fit the "important" information needs of patients.

Table 2 displays the 27 items of the patients' core set as well as sensitivity and specificity of the professional sets with regard to patients' set. Overall, somewhat more than half (51) of the items belong to at least one core set. In particular, eight items of the patients' core set are part of every professional core set too (e.g., "What is prostate cancer?") and another 14 items are part of a majority of professional sets (e.g., "If the prostate cancer is not treated, will it affect my bladder functioning?"). Finally, five items belong to the patients' core set but only to a minority or even none of the professionals' sets (e.g., "If the prostate cancer is not treated, how long will I live?").

Table 3 shows another 21 items being part of at least one professional but not of the patients' core set. Only a few items are part of most professionals' but not of the patient's set. A larger number of 10 items belong only to one professional set.
The concordance of the item sets of patients and professionals is moderate with $\kappa=0.38-0.66$. The sensitivity of professionals' core sets varies between 56 and $74 \%$. Specificity of professionals' judgments is higher (80-89 \%).

\section{Discussion}

Patients newly diagnosed with localized prostate cancer are faced with several treatment options. To decide on a specific therapy is a complex undertaking for patients by having to consider a variety of sophisticated data. The present study explored the correspondence of professionals' information priorities with patients' information needs. We adapted the design and instrument of studies by Feldman-Stewart et al. [5] to a Swiss sample of patients and health professionals. Patients were presented with 92 information topics on prostate cancer and its treatment in order to rate the relevance of these topics with regard to their decision for treatment. Six groups of health professionals involved in the treatment and care of prostate cancer patients were presented with the same items, professionals had to rate the items from the viewpoint of a hypothetical vignette patient. Results are in line with the findings of previous studies [3, 4, 10-12], in particular, of studies by Feldman-Stewart et al. [5, 20], but our study also reveals some further insights. 
Table 2 Patients' core set of items (28 out of 92) with high importance as well as high agreement in relation to professionals' core sets

\begin{tabular}{|c|c|c|c|c|}
\hline Items & $\bar{x}_{\mathrm{i}}$ & $p_{\mathrm{i}}$ & Core sets & Number of sets \\
\hline What is prostate cancer? & 1.90 & 0.85 & $\mathrm{I}-\mathrm{V}$ & 5 \\
\hline If the prostate cancer is not treated, will I die from it? & 1.75 & 0.67 & $\mathrm{I}-\mathrm{V}$ & 5 \\
\hline How long can I safely take to make up my mind? & 1.74 & 0.63 & $\mathrm{I}-\mathrm{V}$ & 5 \\
\hline How long will it take to finish all my treatment? & 1.74 & 0.63 & $\mathrm{I}-\mathrm{V}$ & 5 \\
\hline If I choose radiation treatment, will I have large areas of my body radiated? & 1.75 & 0.68 & $\mathrm{I}-\mathrm{V}$ & 5 \\
\hline How does the treatment work? & 1.81 & 0.73 & $\mathrm{I}-\mathrm{V}$ & 5 \\
\hline When and how will you know if the treatment is working? & 1.80 & 0.71 & $\mathrm{I}-\mathrm{V}$ & 5 \\
\hline Will the treatment affect my bladder control? If so, for how long? & 1.83 & 0.77 & $\mathrm{I}-\mathrm{V}$ & 5 \\
\hline What does PSA mean? & 1.79 & 0.73 & I, III-V & 4 \\
\hline If the prostate cancer is not treated, how fast will it spread? & 1.77 & 0.70 & I-IV & 4 \\
\hline If the prostate cancer is not treated, will it be painful? & 1.61 & 0.52 & I-IV & 4 \\
\hline If the prostate cancer is not treated, will it affect my sexual functioning? & 1.59 & 0.51 & I, II, IV, V & 4 \\
\hline What type of monitoring will there be if I choose no treatment? & 1.65 & 0.58 & I-IV & 4 \\
\hline How long will I have to wait to start treatment? & 1.63 & 0.55 & I-IV & 4 \\
\hline What kind of follow-up will take place after my treatment? & 1.57 & 0.51 & I, III-V & 4 \\
\hline Will the treatment affect my sexual functioning? If so, when and for how long? & 1.66 & 0.56 & I, II, III, V & 4 \\
\hline If the prostate cancer is not treated, what parts of my body could be affected? & 1.73 & 0.64 & I-III & 3 \\
\hline If the prostate cancer is not treated, will it affect my bladder functioning? & 1.73 & 0.63 & I, II, IV & 3 \\
\hline If I do not have the treatment now, can I have it when the cancer gets worse? & 1.59 & 0.52 & I, III, V & 3 \\
\hline What do we do if the cancer comes back? & 1.75 & 0.68 & I, II, III & 3 \\
\hline If the treatment is not successful, what are my options? & 1.79 & 0.73 & I, II, III & 3 \\
\hline If I get one type of treatment, can I have any of the other treatments later? & 1.62 & 0.56 & I, III, V & 3 \\
\hline If more than one treatment is needed, how much time does each treatment take? & 1.62 & 0.53 & $\mathrm{I}, \mathrm{V}$ & 2 \\
\hline When and how will you know if I have been cured? & 1.74 & 0.66 & I, II & 2 \\
\hline If the prostate cancer is not treated, how long will I live? & 1.57 & 0.51 & I & 1 \\
\hline Is the equipment at the hospital up to date for treating the prostate cancer? & 1.59 & 0.52 & I & 1 \\
\hline How experienced is my doctor in treating patients with prostate cancer? & 1.55 & 0.52 & I & 1 \\
\hline Concordance of professionals' core set with patients' core set (27 items) & & Kappa & Sensitivity, \% & Specificity, \% \\
\hline Urologists (28 items) & & $0.66(0.43-0.79)$ & $74.1(53.7-88.9)$ & $87.7(77.2-94.5)$ \\
\hline Nurses (29 items) & & $0.54(0.35-0.73)$ & $70.4(49.8-86.2)$ & $84.6(73.5-92.4)$ \\
\hline RTT (29 items) & & $0.38(0.18-0.59)$ & $59.3(38.8-77.6)$ & $80.0(68.2-88.9)$ \\
\hline Oncologists (22 items) & & $0.47(0.27-0.68)$ & $55.6(35.3-74.5)$ & $89.2(79.1-95.6)$ \\
\hline
\end{tabular}

$\bar{x}_{i}$ : item mean of patients (-1: "avoid"; 0: "no opinion"; 1: "desired"; 2: “essential"); $p_{\mathrm{i}}$ : item-specific raw agreement of patients; core sets: I patients; II nurses; III: urologists; IV RTT; V oncologists

First, information needs of patients with localized prostate cancer are very heterogeneous: whereas some patients are interested in as much information as possible, others report quite limited information needs [5, 26-28]. In addition to the findings of previous research, we have quantified the low agreement among patients in their appraisal of information topics. The low agreement suggests that meeting the highly individual needs of a patient might be a challenging task for the consulting health professional.

Second, the heterogeneity of patients' information needs, however, is mirrored by the information priorities of health professionals. Results of the few studies investigating the role of different health specialists in prostate cancer care [17-19] indicate that how professionals counsel patients as well as what kind of treatment option they favor is highly dependent on their professional background. Our study presents findings for six groups of specialists indicating that, no matter what specific professional background, health professionals do only weakly agree among each other on information topics of importance for patients. We did not corroborate the findings of Capirci et al. [21] indicating that the central tendencies of appraisals by professionals are more consistent among each other than with the central tendencies of the patients' judgments; however, what is consistent with both that study and with Feldman-Stewart's study of professionals in Canada [26] is the wide differences in the judgments within each profession. 
Table 3 Items belonging to at least one professional core set but not to the patients' core set

\begin{tabular}{|c|c|c|c|c|}
\hline Items & $\bar{x}_{i}$ & $p_{\mathrm{i}}$ & Core sets & Number of sets \\
\hline Will I receive medication for symptom control? & 1.46 & 0.44 & II-V & 4 \\
\hline If I choose radiation treatment, should I take hormone pills before the radiation? & 1.54 & 0.54 & III-V & 3 \\
\hline If I delay treatment, is there a chance I can still be cured? & 1.55 & 0.50 & III-V & 3 \\
\hline Will the treatment cause pain? If so, for how long? & 1.55 & 0.49 & II, III, IV & 3 \\
\hline What options/treatments do I have if my impotency is permanent? & 1.56 & 0.50 & II, III, V & 3 \\
\hline If the prostate cancer is not treated, will it disappear on its own? & 1.55 & 0.52 & II, IV & 2 \\
\hline Where will I go for the treatment? & 1.42 & 0.42 & II, IV & 2 \\
\hline Can I continue my exercise program during treatment? & 1.48 & 0.45 & II, IV & 2 \\
\hline Do I continue taking medications (prescribed and over-the-counter) during treatment? & 1.54 & 0.49 & II, IV & 2 \\
\hline If I delay treatment, will any treatment help me? & 1.49 & 0.48 & III, V & 2 \\
\hline Could the treatment lead to my death? & 1.49 & 0.50 & III, V & 2 \\
\hline Are my sons at risk of developing prostate cancer? & 1.08 & 0.32 & III & 1 \\
\hline If the prostate cancer is not treated, will I still be able to carry on my usual activities? & 1.49 & 0.46 & II & 1 \\
\hline Will I get the same level of care regardless of my treatment decision? & 1.32 & 0.39 & $\mathrm{~V}$ & 1 \\
\hline Can I have sex during the course of treatment? & 1.46 & 0.44 & II & 1 \\
\hline Will I see my doctor during the treatment? & 1.20 & 0.35 & IV & 1 \\
\hline Will I lose my gonads/testicles? & 1.43 & 0.44 & II & 1 \\
\hline Will the treatment make me tired? If so, for how long? & 1.23 & 0.36 & IV & 1 \\
\hline Will the treatment cause diarrhea? If so, for how long? & 1.29 & 0.37 & IV & 1 \\
\hline Will the treatment cause bleeding? If so, for how long? & 1.45 & 0.43 & IV & 1 \\
\hline Will the treatment affect my bowel control? If so, for how long? & 1.45 & 0.44 & IV & 1 \\
\hline
\end{tabular}

$\bar{x}_{i}$ : item mean of patients (-1: "avoid"; 0: "no opinion"; 1: "desired"; 2: “essential”); $p_{\mathrm{i}}$ : item-specific raw agreement of patients; core sets: I patients; II nurses; III: urologists; IV RTT; V oncologists

Taking into account the modest within-group agreement of patients as well as of all groups of participating health professionals, it is not surprising that between-group agreement is modest too, i.e.: not only do the appraisals of health professionals correspond only moderately with the patient needs but also different groups of professionals agree only modestly with each other on information priorities.

Third, despite the heterogeneity of the information needs of patients as well as the priorities of professionals, we tried to build core sets of items vital to at least one group of study participants. Applying the rule that a specific item has to be rated highly and with strong consensus results in around half (51 of 92) of the presented information topics being part of at least one core set of a specific group. Correspondence between patients' and professionals' ratings of core set information topics is more pronounced compared to the agreement on the entire item pool. The majority $(81 \%)$ of the information topics within the patient core set are also part of at least three out of five core sets of professionals. Thus, in addition to the findings of other studies $[21,26,29]$, we can conclude that there are some information topics on prostate cancer and its therapy with high relevance and substantial consensus among patients as well as professionals.

Some methodological limitations of the present study are to be mentioned: (1) It can be argued that the heterogeneous appraisals of information topics on prostate cancer is at least in some part induced by the questionnaire being used. Because it was designed to reflect a broad range of information needs of patients [5], high or already substantial agreement on all of the 92 items presented can hardly be expected. (2) The rating scale of the information topics may not allow for a sufficiently differentiated appraisal. In fact, the scale does not seem to display the complete range of possible ratings: subjects were provided with two categories for positive ("essential," "desired"), one category for indifferent ("no opinion"), and another one for negative ("to avoid") appraisal. Moreover, the negative category does not seem to represent the same dimension with regards to content as the positive categories do. However, the fact that some participants identified some items to be "avoided" suggests that adding a negative response option is an important addition to the more typical assessments of information needs that just elicit ratings from "not important" to "very important" [4]. (3) The sample of patients selected for participation might be too heterogeneous with regard to onset of disease. (4) Patients were asked to rate the importance of each item retrospectively regarding their decision making on choosing a specific treatment option. Therefore, we have to take into account a recall bias, meaning that memories of what kind of information on treatment that had been important may differ substantially as a function of the time since diagnosis. (5) Finally, the previous course of 
disease and therapy will influence the appraisal of information on its nature and treatment options.

\section{Conclusions}

Information needs with regard to treatment decision of men suffering from curable prostate cancer are broad, but very individual too. Although it is possible to reduce information about this disease on a core set of topics vital for patients, this will always result in a substantial number of men with information needs not sufficiently covered [30]. Our findings emphasize the function of the dialogue between doctor/ professional and patient in providing information on a highly individual level and support the importance of shared decision making [7]. Counseling of prostate cancer patients by standardized guidelines only but also require sensitivity to the patients' needs [31].

Furthermore, results suggest that health professionals even within the same speciality counsel men suffering from prostate cancer quite inconsistently [6, 32]. A good working exchange between different doctors as well as other professionals caring for patients seems to be of particular importance. Case management approaches to the care and coaching of cancer patients [33] as well as multidisciplinary counseling could be helpful to reach this goal [13-15]. In addition, the use of web-based tools in the field of prostate cancer counseling [32] could offer new ways of individually and flexibly tailoring knowledge transfer from professionals to patients [34].

Acknowledgments This study was supported by the Swiss Cancer League and Swiss Cancer Research (project number: KLS-02198-022008). We would like to thank all of the patients who participated in the study.

\section{Appendix}

Calculation of between-group rater agreement based on within-group rater agreement

$$
C_{1 \times 2}=\frac{C_{1+2}-\left(\left(C_{1} * w_{1}\right)+\left(C_{2} * w_{2}\right)\right)}{w_{1 \times 2}}
$$

with:

- $C_{1 \times 2}=$ between-group agreement coefficient of group 1 ratings paired with group 2 ratings

- $C_{1+2}=$ total agreement coefficient of pooled group 1 and group2 ratings

- $C_{1}, C_{2}=$ within-group agreement coefficients of group 1 and group 2
- $w_{1}, w_{2}, \mathrm{w}_{1 \times 2}=$ weights for group 1 and 2 as wells as for the combination of both groups.

$w_{1}=$ weighted number of rating pairs in group 1

$w_{1}=\frac{\frac{\left(n_{1} *\left(n_{1}-1\right)\right)}{2}}{\frac{\left(n_{\mathrm{a}} *\left(n_{\mathrm{a}}-1\right)\right)}{2}}=\frac{\left(n_{1} *\left(n_{1}-1\right)\right) * 2}{\left(n_{\mathrm{a}} *\left(n_{\mathrm{a}}-1\right)\right) * 2}=\frac{\left(n_{1} *\left(n_{1}-1\right)\right)}{\left(n_{\mathrm{a}} *\left(n_{\mathrm{a}}-1\right)\right)}$

$w_{2}=$ weighted number of rating pairs in group 2

$w_{2}=\frac{\left(n_{2} *\left(n_{2}-1\right)\right)}{\left(n_{\mathrm{a}} *\left(n_{\mathrm{a}}-1\right)\right)}$

$w_{1 \times 2}=$ weighted number of rating pairs of group 1 and group 2 each

$w_{1 \times 2}=\frac{\left(n_{\mathrm{a}}-\left(n_{\mathrm{a}}-1\right)\right)-\left(\left(n_{1}-\left(n_{1}-1\right)\right)+\left(n_{2}-\left(n_{2}-1\right)\right)\right)}{\left(n_{\mathrm{a}}-\left(n_{\mathrm{a}}-1\right)\right)}$

- $n_{1}=$ number of raters in group 1

- $n_{2}=$ number of raters in group 2

- $\quad n_{\mathrm{a}}=$ total number of raters in group 1 and group 2

Open Access This article is distributed under the terms of the Creative Commons Attribution Noncommercial License which permits any noncommercial use, distribution, and reproduction in any medium, provided the original author(s) and the source are credited.

\section{References}

1. Heidenreich A, Bellmunt J, Bolla M, Joniau S, Mason M, Matveev V et al (2011) EAU guidelines on prostate cancer. Part 1: screening, diagnosis, and treatment of clinically localised disease. Eur Urol 59: 61-71

2. Wilt TJ, MacDonald R, Rutks I, Shamliyan TA, Taylor BC, Kane RL (2008) Systematic review: comparative effectiveness and harms of treatments for clinically localized prostate cancer. Ann Intern Med 18(148):435-448

3. Davies NJ, Kinman G, Thomas RJ, Bailey T (2008) Information satisfaction in breast and prostate cancer patients: implications for quality of life. Psycho-Oncology 17(10):1048-1052

4. Dale J, Jatsch W, Hughes N, Pearce A, Meystre C (2004) Information needs and prostate cancer: the development of a systematic means of identification. BJU Int 94(1):63-69

5. Feldman-Stewart D, Brundage MD, Hayter C, Groome P, Nickel JC, Downes $\mathrm{H}$ et al (2000) What questions do patients with curable prostate cancer want answered? Med Decis Making 20(1):7-19

6. Zeliadt SB, Ramsey SD, Penson DF, Hall IJ, Ekwueme DU, Stroud L et al (2006) Why do men choose one treatment over another?: a review of patient decision making for localized prostate cancer. Cancer 106(9):1865-1874

7. Gwede CK, Pow-Sang J, Seigne J, Heysek R, Helal M, Shade K et al (2005) Treatment decision-making strategies and influences in patients with localized prostate carcinoma. Cancer 104(7):1381-1390

8. McGregor S (2003) What information patients with localised prostate cancer hear and understand. Patient Educ Couns 49(3):273-278 
9. Gattellari M, Butow PN, Tattersall MH (2001) Sharing decisions in cancer care. Soc Sci Med 52:1865-1878

10. Cegala DJ, Bahnson RR, Clinton SK, David P, Gong MC, Monk JP et al (2008) Information seeking and satisfaction with physicianpatient communication among prostate cancer survivors. Health Commun 23(1):62-69

11. Snow SL, Panton RL, Butler LJ, Wilke DR, Rutledge RD, Bell DG et al (2007) Incomplete and inconsistent information provided to men making decisions for treatment of early-stage prostate cancer. Urology 69(5):941-945

12. Davison BJ, Goldenberg SL, Gleave ME, Degner LF (2003) Provision of individualized information to men and their partners to facilitate treatment decision making in prostate cancer. Oncol Nurs Forum 30(1):107-114

13. Gomella LG, Lin J, Hoffman-Censits J, Dugan P, Guiles F et al (2010) Enhancing prostate cancer care through the multidisciplinary clinic approach: a 15-year experience. J Oncol Pract 6(6):e5-e10. doi:10.1200/jop.2010.000071

14. Valdagni R, Albers P, Bangma C, Drudge-Coates L, Magnani Tea (2011) The requirements of a specialist prostate cancer unit: a discussion paper from the European School of Oncology. Eur J Cancer 47(1). doi:10.1016/j.ejca.2010.10.029

15. Strebel RT, Sulser T, Schmid H-P, Gillessen S, Fehr M et al (2013) Multidisciplinary care in patients with prostate cancer: room for improvement. Support Care Cancer 21(8):2327-2333. doi:10.1007/ s00520-013-1791-x

16. Tarrant C, Sinfield P, Agarwal S, Baker R (2008) Is seeing a specialist nurse associated with positive experiences of care? The role and value of specialist nurses in prostate cancer care. BMC Health Serv Res 8:65. doi:10.1186/1472-6963-8-65

17. Fowler FJ, McNaughton Collins M, Albertsen PC, Zietman A, Elliott DB et al (2000) Comparison of recommendations by urologists and radiation oncologists for treatment of clinically localized prostate cancer. JAMA 283(24):3217-3222. doi:10.1001/jama.283. 24.3217

18. Sommers BD, Beard CJ, D'Amico AV, Kaplan I, Richie JP et al (2008) Predictors of patient preferences and treatment choices for localized prostate cancer. Cancer 113(8):2058-2067. doi:10.1002/ cncr.23807

19. Jang TL, Bekelman JE, Liu Y, Bach PB, Basch EM (2010) Physician visits prior to treatment for clinically localized prostate cancer. Arch Intern Med 170(5):440-450

20. Feldman-Stewart D, Capirci C, Brennenstuhl S, Tong C, Abacioglu U, Gawkowska-Suwinska M et al (2010) Information needs of early- stage prostate cancer patients: a comparison of nine countries. Radiother Oncol 94(3):328-333

21. Capirci C, Feldman-Stewart D, Mandoliti G, Brundage M, Belluco G, Magnani K (2005) Information priorities of Italian early-stage prostate cancer patients and of their health-care professionals. Patient Educ Couns 56(2):174-181

22. Fleiss JL (1971) Measuring nominal scale agreement among many raters. Psychol Bull 76(5):378-382

23. Cohen J (1960) A coefficient for agreement for nominal scales. Educ Psychol Meas 20:37-46

24. Feinstein AR, Cicchetti DV (1990) High agreement but low kappa: I. The problems of two paradoxes. J Clin Epidemiol 43:543-549

25. Gwet KL (2008) Computing inter-rater reliability and its variance in the presence of high agreement. B J Math Stat Psychol 61:29-48

26. Feldman-Stewart D, Brundage MD, Hayter C, Groome P, Nickel JC, Downes $\mathrm{H}$ et al (1998) What prostate cancer patients should know: variation in professionals' opinions. Radiother Oncol 49(2):111-123

27. Feldman-Stewart D, Brennenstuhl S, Brundage MD, Siemens DR (2009) Overall information needs of early-stage prostate cancer patients over a decade: highly variable and remarkably stable. Support Care Cancer 17(4):429-435

28. Schaffert R, Ruesch P, Gugler R, Fischer S, Schmid HP, Sporri P et al (2011) Informationsbedurfnisse von Prostatakrebspatienten [Information needs of patients with prostate cancer]. Urologe 50(9): 1089-1094

29. Feldman-Stewart D, Capirci C, Brundage MD (2003) Information for patients with early-stage prostate cancer: a comparison of professionals' attitudes in Canada and Italy. Support Care Cancer 11(7): 472-480. doi:10.1007/s00520-003-0462-8

30. Feldman-Stewart D, Brundage MD (2004) Challenges for designing and implementing decision aids. Patient Educ Couns 54(3):265-273

31. Dahm P, Yeung LL, Chang SS, Cookson MS (2008) A critical review of clinical practice guidelines for the management of clinically localized prostate cancer. J Urology 180(2):451-459

32. Chamie K, Saigal CS, Litwin MS (2011) Patients and solipsism: the psychology of decision making for prostate cancer treatment. Urol Oncol 29(3):233-234

33. Wulff CN, Thygesen M, Søndergaard J, Vedsted P (2008) Case management used to optimize cancer care pathways: a systematic review. BMC Health Serv Res 8:227

34. Feldman-Stewart D, Brundage MD, Van Manen L, Svenson O (2004) Patient-focussed decision-making in early-stage prostate cancer: insights from a cognitively based decision aid. Health Expect 7(2):126-141 